Journal of Research in Technical Careers

May 2020, Vol. 4, No. 1.

(C) Author(s)

\title{
Addressing the Gender Gap: Women's Perceived Barriers to Pursuing STEM Careers
}

\author{
Marshall Swafford ${ }^{\mathrm{a}}$, Ryan Anderson ${ }^{\mathrm{b}}$ \\ ${ }^{a}$ Eastern New Mexico University, ${ }^{b}$ Texas State University
}

\begin{abstract}
This national study used the Delphi method to identify perceived barriers women face in the pursuit of STEM careers. The study used a series of three web-based questionnaires. The first round of the study used a questionnaire with an open-ended question to facilitate the generation of a wide array of response categories. In round two, respondents were asked to rate the 24 perceived barriers from round one on a Likert-type scale and to make changes as necessary. In round three, respondents were asked to provide a dichotomous indication of whether they agreed or disagreed with each of the items. Consensus on 22 perceived barriers was reached after three rounds. The major barriers identified by the respondents were: male domination of STEM careers, lack of awareness of educational and career opportunities, STEM education and toys directed at boys, a lack of female mentors/role models, minimization of barriers, personal expectations, the time required to become proficient in a STEM field, lack of encouragement from men, and the perceived glass ceiling of women in STEM careers. It is recommended that future research focus on the efficacy of formal, informal, and non-formal education models toward increasing awareness of educational and career opportunities in STEM. Researching effective methods to recruit and retain females in STEM degree programs is also suggested.
\end{abstract}

Keywords: STEM, women in STEM, STEM career barriers, gender differences in STEM

As America is fully engaged in the 21st century, its ability to maintain global competitiveness within science, technology, engineering, and mathematics (STEM) hinges on a fully developed economy (Carnevale, Smith, \& Melton, 2011). Workers with STEM knowledge and skills play an important role in driving innovation and economic growth (Rothwell, 2013). Since the industrial revolution, economies have become increasingly wealthy and complex with scientists, engineers, and other STEM workers becoming more important to the labor market (Rothwell, 2014). Nonetheless, the number of students pursuing STEM careers still lags behind the demand both in the United States and internationally (Rothwell, 2014; U.S. Department of Labor, 2009). To combat this issue, Presidents George W. Bush and Barack Obama proposed and advocated polices and initiatives to increase the supply of qualified STEM workers (Rothwell, 2014). Although these policies and initiatives have yielded increased numbers of qualified workers, men continue to outnumber women in these careers (Hill, Corbett, \& St. Rose, 2010), which has 
Journal of Research in Technical Careers

resulted in calls to increase the proportion of women in STEM education and careers (Roberts, Harder, \& Brashears, 2016).

\section{Gender Gaps by STEM Field}

The foundation of the gender discrepancy among STEM workers can be identified as early as middle school. Historically, girls have been outperformed by boys in math; however, over the past few decades, the gender gap has narrowed, and now the differences are negligible (Hyde, Lindberg, Linn, Ellis, \& Williams, 2008). Currently, boys and girls are earning math and science credits at an equal rate with girls earning slightly higher grades (U.S. Department of Education, National Center for Education Statistics (NCES), 2007). However, a small gender gap persists on the mathematics sections of the SAT and ACT examinations (Corbett, Hill, \& St. Rose, 2008). Furthermore, boys take more advanced placement exams in STEM-related areas than girls (Hill et al., 2010). The gender gap continues to increase when students reach postsecondary education. While women are the majority of college students, the percentage of men pursuing STEM degrees outpaced women $29 \%$ to $15 \%$ among incoming freshmen (National Science Foundation, 2009). When biological sciences are not included, the gap becomes more pronounced with only $5 \%$ of female freshman planning to major in engineering, computer science, or the physical sciences (National Science Foundation, 2009).

Similar to men, women who enroll as STEM majors tend to be well-qualified (Hill et al., 2010) and persist at comparable rates (Seymour \& Hewitt, 1997). Approximately one half of the bachelor's degrees in chemistry, math, and agriculture are awarded to women (NCES, 2015; National Science Board, 2014). However, among degrees awarded in physics, engineering, and computer science, this proportion decreases to approximately $20 \%$ (National Science Board, 2014). Moreover, there has been a steady decline in women earning bachelor's degrees in computer science with females earning $28 \%$ of degrees conferred in 2000 compared to 17\% of degrees in 2011 (National Science Board, 2014).

Consistent with the increased representation of women earning degrees in STEM fields, the proportion of women employed in the workforce has improved but varies among areas (USDA, 2014). Women comprise over 50\% of biological scientists, but women account for approximately one in ten professionals among traditional engineering professions (U.S. Department of Labor, 2016). Although the number of women in production agriculture has tripled since the 1980 s and comprises $30 \%$ of the workforce, since 2007 the number of women in that employment sector has decreased by $2 \%$ (USDA, 2014). Among academic faculty, women's representation varies by discipline and tenure status (Hill et al., 2010). In 2005, women accounted for $40 \%$ of full-time STEM faculty at degree-granting institutions yet comprised less than $25 \%$ of the faculty in computer and information sciences $(22 \%)$, mathematics (19\%), physical sciences $(18 \%)$, and engineering $(12 \%)$. Unlike non-academic biological science careers, women make up only one-third of the faculty (Hill et al., 2010). As would be expected based upon the recent increase among women in STEM academia, women were better represented in lower faculty ranks than higher ranks (DiFabio, Brandi, \& Frehill, 2008). 


\section{Barriers to Women Pursuing STEM Careers}

Researchers have identified several factors that impact the proportion of women in STEM careers, with those factors falling under three primary themes: 1) men's perceived superiority in mathematics and career field suitability, 2) girls'/women's perceived lack of interest, and 3) workplace issues ranging from work-life balance to bias (Hill et al., 2010). Even though the differences in mathematics performance between girls and boys has largely moderated (Hyde et al., 2008), the issue of cognitive gender differences remains contested (Hill et al., 2010). The notion of boys being smarter has been debunked, as Lynn and Irwing (2004) found little or no differences in average IQ between males and females. However, boys have consistently outscored girls on spatial skills tests (Linn \& Peterson, 1985), while girls have outperformed boys on tests involving writing, memory, and perceptual speed (Halpern et al., 2007; Hedges \& Nowell, 1995; Kimura, 2002). Biologically, Ceci, Williams, and Barnett (2009) found the influence of brain structure and hormonal differences between males and females to be inconclusive when used as variables to explain the underrepresentation of women in STEM careers.

Sociocultural factors and math achievement have been examined as factors attempting to explain the gender gap. (Andreescu, Gallian, Kane, \& Mertz, 2008; Hill et al., 2010). In a majority of countries, more boys than girls scored above the $99^{\text {th }}$ percentile in mathematics on the 2003 Program for International Student Assessment yet girls more often scored above the same threshold in Iceland and Thailand (Guiso, Monte, Sapienza, $\&$ Zingales, 2008). These differences between countries illustrate the cultural importance of mathematical skill development (Hill et al., 2010). Researchers have suggested that gender differences in mathematics test scores accounts for the limited number of women in certain STEM fields (Hill et al., 2010). However, as Weinberger (2005) pointed out, less than one-third of college-educated white men in engineering, mathematics, computer science, and physical sciences scored higher than 650 on the SAT math exam, with more than one-third scoring below 550, the score of the average humanities major. While a relationship exists between mathematics test scores and entry into STEM education and careers, high test scores are not necessarily a prerequisite for success in these fields (Hill et al., 2010).

According to Hill et al. (2010), both girls and women have expressed a lack of desire to pursue STEM careers. In a recent poll of students aged 8-17, 24\% of boys, but only 5\% of girls, expressed interest in engineering careers (American Society for Quality, 2009). Another poll found $74 \%$ of college-bound boys identified computer-focused college majors would be a good fit for them compared to $32 \%$ of their female contemporaries (WGBH Education Foundation \& Association for Computing Machinery, 2009). Even among high math achieving girls and women, pursuit of degrees in math, computer science, engineering, or the physical sciences are far exceeded by secured degrees in humanities, life sciences, and social sciences (Lubinski \& Benbow, 2006). Belief in potential success, self-confidence in STEM subjects, and perceived gender roles can influence interest in careers (Eccles, 2006; Low, Yoon, Roberts, \& Rounds, 2005; Pajares, 2005). Although girls are equivalent in mathematical achievement, they tend to hold themselves to higher standards than boys (Hill et al., 2010). Pajares (2005) found the gender differences in 
academic self-confidence begin in middle school and increase throughout high school and college, with girls reporting less confidence in their math and science abilities. However, as Dweck (2006) noted, when girls believe that they can become smarter and learn what they need to know in STEM subjects, they are more likely to succeed in these fields. Finally, culturally prescribed gender roles influence career interest, especially in girls, by suggesting certain career options are not possible because they are inappropriate for their gender (Hartung, Porfeli, \& Vondracek, 2005; Low et al., 2005).

Workplace environment, bias, and family responsibilities influence women's desires to pursue and remain in STEM careers (Hill et al., 2010). Women have reported isolation, unsupportive work environments, extreme work schedules, and ambiguous rules about advancement and success as factors in their decisions to leave STEM careers (Hewlett et al., 2008). In academia, turnover has been attributed to dissatisfaction with departmental culture, advancement opportunities, faculty leadership, and lack of research support (Xu, 2008). Although instances of explicit bias may be decreasing, implicit bias in society, and specifically in the workplace, continues to deter women from pursuing and remaining in STEM careers (Hill et al., 2010). Even those who support gender equity and equality may hold implicit biases about gender and thus hold negative gender stereotypes about females in science and mathematics (Valian, 1998). However, the literature reveals family and marriage can have both positive and negative impacts on women's careers. While marriage is positively related to securing a STEM career or receiving tenure and promotion (Ginther \& Kahn, 2006), having young children appears to have a negative impact (Xie \& Shauman, 2003). Women are affected more negatively than men by the "family penalty" (Simard, Henderson, Gilmartin, Schiebinger, \& Whitney, 2008, p. 5) as childcare responsibilities fall disproportionally on women, and thus women are perceived as less productive (Stack, 2004).

\section{Theoretical Framework}

This study was guided by the Theory of Vocational Personalities and Work Environments (Holland, 1997). Holland posited that individuals tend to seek and create work environments that allow them to manifest their work personalities (Su, Murdock, \& Rounds, 2015). Holland (1997) identified six work personality types, also known as vocational interests (Su, Murdock, \& Rounds, 2015), which influence one's career decisions: realistic, investigative, artistic, social, enterprising, and conventional. Holland illustrated these personality types around a hexagonal model to visually reflect the degree of similarity between them, e.g., artistic and social are similar to each other, where investigative and enterprising, being directly across from each other on the hexagon, are maximally different (Figure 1). Holland (1997) also categorized work environments into the six personality types. Holland argued that the degree of congruence between a person's personality and interest type and their work environment affects work attitudes and behaviors. Thus, higher levels of congruence lead to greater satisfaction, success, and persistence (Su, Murdock, \& Rounds, 2015). We operationalize that the findings in this 


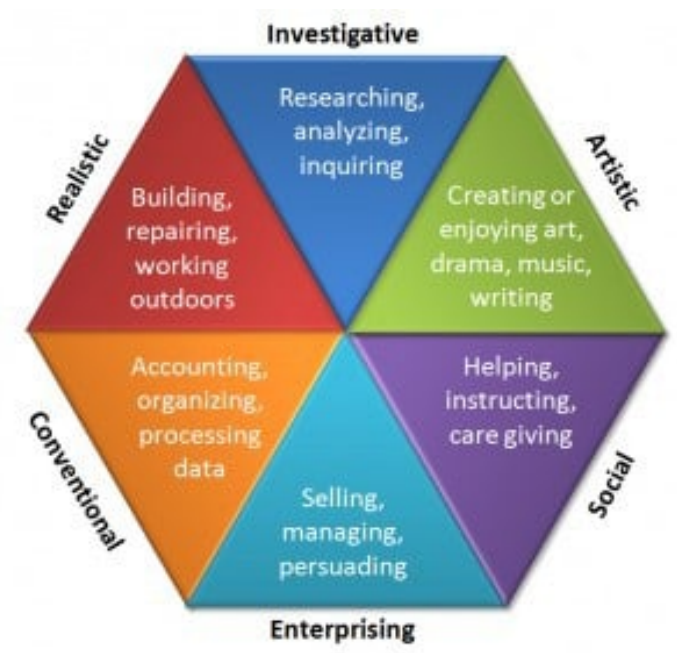

Figure 1. Holland's six work personality types. Adapted from Making Vocational Choices: A Theory of Vocational Personalities and Work Environments, by J. L. Holland, 1997, Odessa, FL: Psychological Assessment Resources.

study will identify the work attitudes and behaviors that are creating barriers for woman that are contributing to the gender gap in STEM careers.

\section{Objective}

The gender gap in STEM careers continues to be an important and complex issue facing the United States workforce. Therefore, the objective of this study was to identify the barriers women perceive as obstacles to successful employment in STEM careers. The purpose of this study addressed the American Association of Agricultural Educators (AAAE) National Research Agenda Priority Area 3: "Sufficient Scientific and Professional Workforce That Addresses the Challenges of the 21st Century" (Stripling \& Roberts, 2016, p. 29). This research purpose also aligns with the National Career and Technical Education Research Agenda (Lambeth, Elliot, \& Joerger, 2008) research problem area (RPA) 2: Curricula and Program Planning, specifically relating to research activity (RA) 2.2.1 Needs of Future Workforce and in RA 2.3.1: Employment, Supply-Demand and Nature of Workforce.

\section{Method}

This national study used the Delphi method to identify perceived barriers women face in pursuing STEM careers as determined by a panel of experts. Delp, Thesen, Motiwalla, and Seshadri (1977) described the Delphi method as a group process by which 
a panel of experts is assembled to provide informed judgment toward consensus on a specific topic. The purpose of a Delphi panel is to collect responses from a group of experts and combine the responses into a useful statement (Stitt-Gohdes \& Crews, 2004).

An all-female, three-member advisory panel consisting of an engineer, neuroscientist, and a university humanities professor was used to assist in the selection of the study's panel of experts. The goal of the advisory panel was to select women who were employed in and out of STEM fields. Women who had originally pursued STEM careers but who were, at the time of the study, engaged in non-STEM careers were selected to participate to provide broader range of barriers. The panel of experts consisted of women with academic and career experiences related and unrelated to STEM, including finance, elementary and higher education, computer science, engineering, agriculture, mathematics, law, art, business, and medicine. To ensure a representative sample, eight women were selected from each region (North Central, Southern, and Western) of the American Association for Agricultural Education (AAAE) for a total of 24 panelists. Dalkey (1969) reported that the reliability was greater than .80 when Delphi group size was larger than 13.

Upon agreement of the panelists to participate, this study employed three rounds and was initiated through an email detailing the process and anticipated timeline. The study was conducted electronically via an online data collection instrument. Each round was closed after 21 days, and data collection was closed after 63 days. The first round of the study used a questionnaire with the open-ended question: "What are the major obstacles confronting women in the pursuit of careers in STEM?" An open-ended question was used to facilitate the generation of a wide array of response categories. At the conclusion of this round, 68 obstacles were identified. These obstacles were then categorized into themes by the researcher and the members of the advisory panel, which resulted in 24 items for a second-round questionnaire. Interrater reliability (Ary, Jacobs, Razavieh, \& Sorenson, 2006) was established by reconciling differences through consensus. Questionnaires were validated using an expert panel of university social science researchers.

In the second questionnaire, panelists were asked to rate the perceived barriers identified in round one on a 5-point Likert-type scale $(1=$ Strongly Disagree, $2=$ Disagree, 3= Uncertain, 4= Agree, 5= Strongly Agree). The second questionnaire was sent to only those who had participated in the first round. From second-round responses, the list of perceived barriers was reduced from 24 to 22 . The third questionnaire sought to determine consensus. This questionnaire was sent to only those who had participated in the second round. Respondents were provided with both their own individual ratings and those of the group from round two. Panel members were asked to indicate whether they agreed or disagreed with each of the 22 perceived barriers and to provide comments if they did not agree with the summary findings. Consensus was reached on 22 barriers with no suggested revisions, and thus, data collection ceased. Data were analyzed using descriptive statistics. Data collected using Likert-type scales were treated as interval data and reported as means and standard deviations. Nominal data were reported using frequencies and percentages. 
Table 1. Delphi Study Round One: Obstacles Confronting Women in the Pursuit of Careers in STEM $(n=21)$

\begin{tabular}{l}
\hline Perceived Barrier \\
Intimidation by men \\
Sexism \\
Lack of respect for women in STEM careers \\
Male domination in STEM careers \\
Work/life balance \\
Societal gender roles \\
Personal expectations \\
Time required to become proficient in a STEM field \\
Energy required to become proficient in a STEM field \\
Lack of encouragement from men \\
Lack of encouragement from women \\
Lack of encouragement from family members \\
Lack of encouragement from friends \\
Lack of encouragement from teachers \\
Females perceived level of intelligence \\
STEM toys directed at boys \\
STEM education directed at boys \\
Career wage gap \\
Lack of awareness of educational opportunities in STEM fields \\
Lack of awareness of career opportunities in STEM fields \\
Educational expenses associated with earning a STEM-related degree \\
Lack of female mentors/role models \\
Minimization of barriers \\
Perceived glass ceiling of women in STEM careers \\
\end{tabular}

\section{Results}

For the first round of the study, the response rate for the open-ended questionnaire was $88 \%(n=21)$. Twenty-four perceived barriers were identified in the first round (Table 1).

In the second round of the study, 18 of the 21 panelists responded for an $86 \%$ response rate. As noted in Table 2, respondents agreed or were uncertain on 22 items that were initially considered to be barriers. Two were ranked "Disagree" and were eliminated from the study as barriers to pursing STEM careers. Statements with the highest means centered on patriarchy, work/life balance, lack of awareness of opportunities in STEM, and personal expectations. Respondents disagreed that lack of encouragement from friends and teachers were barriers women faced when pursuing STEM careers.

In round three, 18 panelists from round two were asked to provide commentary on the results from round two. Eighteen of 18 remaining panelists participated in this round for a $100 \%$ response rate for round three. 
Table 2. Delphi Study Round Two: Level of Agreement with Ranked Barriers to STEM Careers $(n=18)$

\begin{tabular}{|c|c|c|c|}
\hline Perceived Barrier & $M$ & $S D$ & $\begin{array}{l}\text { Level of } \\
\text { Agreement }\end{array}$ \\
\hline Male domination in STEM careers & 4.31 & .63 & Agree \\
\hline Lack of awareness of educational opportunities in STEM fields & 4.23 & 1.01 & Agree \\
\hline Lack of awareness of career opportunities in STEM fields & 4.15 & .99 & Agree \\
\hline Work/life balance & 3.92 & .64 & Agree \\
\hline Time required to become proficient in a STEM field & 3.85 & .69 & Agree \\
\hline Lack of female mentors/role models & 3.77 & .93 & Agree \\
\hline Personal expectations & 3.77 & 1.01 & Agree \\
\hline Sexism & 3.69 & .75 & Agree \\
\hline Lack of respect for women in STEM careers & 3.69 & .95 & Agree \\
\hline Perceived glass ceiling of women in STEM careers & 3.62 & .96 & Agree \\
\hline Career wage gap & 3.54 & 1.20 & Agree \\
\hline Societal gender roles & 3.46 & 1.40 & Uncertain \\
\hline Educational expenses associated with earning a STEM-related degree & 3.38 & 1.26 & Uncertain \\
\hline Minimization of barriers & 3.31 & .75 & Uncertain \\
\hline Energy required to become proficient in a STEM field & 3.31 & 1.03 & Uncertain \\
\hline Intimidation by men & 3.23 & 1.30 & Uncertain \\
\hline Lack of encouragement from men & 3.15 & 1.50 & Uncertain \\
\hline Lack of encouragement from family members & 3.15 & 1.57 & Uncertain \\
\hline Females perceived level of intelligence & 3.08 & 1.19 & Uncertain \\
\hline Lack of encouragement from women & 3.08 & 1.44 & Uncertain \\
\hline STEM education directed at boys & 2.85 & 1.46 & Uncertain \\
\hline STEM toys directed at boys & 2.69 & 1.44 & Uncertain \\
\hline Lack of encouragement from friends & 2.46 & 1.27 & Disagree \\
\hline Lack of encouragement from teachers & 2.23 & 1.36 & Disagree \\
\hline
\end{tabular}

Note. ${ }^{\mathrm{a}} 1.00-1.49=$ Strongly Disagree, $1.50-2.49=$ Disagree, $2.50-3.49=$ Uncertain,

$3.50-4.49=$ Agree, $4.50-5.00=$ Strongly Agree.

As shown in Table 3,100\% of the round three panel members agreed that perceived male domination of STEM careers was an obstacle that women face when pursuing STEM careers. Additionally, over $90 \%$ of the panel members agreed that a lack of awareness of educational and career opportunities was a perceived barrier. Furthermore, over $75 \%$ of the panelists agreed that STEM education and toys directed at boys, a lack of female mentors/role models, minimization of barriers, personal expectations, the time required to become proficient in a STEM field, lack of encouragement from men, and the perceived glass ceiling of women in STEM careers were barriers that may prevent women from pursuing STEM careers. On the other hand, less than one half of the panelists agreed that lack of encouragement by family members and perceived lack of intelligence were barriers facing women in STEM. 
Table 3. Delphi Round Three: Level of Agreement with Perceived Barriers to STEM Careers $(n=18)$

\begin{tabular}{lcc}
\hline Perceived Barrier & $\begin{array}{l}\text { Agree } \\
(\%)\end{array}$ & $\begin{array}{l}\text { Disagree } \\
(\%)\end{array}$ \\
\hline Male domination in STEM careers & 100.0 & 0.0 \\
Lack of awareness of educational opportunities in STEM fields & 94.4 & 5.6 \\
Lack of awareness of career opportunities in STEM fields & 94.4 & 5.6 \\
STEM toys directed at boys & 88.9 & 11.1 \\
Lack of female mentors/role models & 88.9 & 11.1 \\
STEM education directed at boys & 83.3 & 16.7 \\
Minimization of barriers & 83.3 & 16.7 \\
Personal expectations & 77.8 & 22.2 \\
Time required to become proficient in a STEM field & 77.8 & 22.2 \\
Lack of encouragement from men & 77.8 & 22.2 \\
Perceived glass ceiling of women in STEM careers & 77.8 & 22.2 \\
Intimidation by men & 72.2 & 27.8 \\
Societal gender roles & 72.2 & 27.8 \\
Lack of respect for women in STEM careers & 66.7 & 33.3 \\
Lack of encouragement from women & 66.7 & 33.3 \\
Career wage gap & 66.7 & 33.3 \\
Sexism & 61.1 & 38.9 \\
Energy required to become proficient in a STEM field & 61.1 & 38.9 \\
Educational expenses associated with earning a STEM-related degree & 61.1 & 38.9 \\
Work/life balance & 55.6 & 44.4 \\
Lack of encouragement from family members & 44.4 & 55.6 \\
Females perceived level of intelligence & 44.4 & 55.6 \\
\hline
\end{tabular}

\section{Conclusions/Discussion/Recommendations}

In this study, the panelists identified several perceived obstacles women may encounter in the pursuit of STEM careers and included: patriarchy, lack of awareness of opportunities, STEM activities and products directed at males, sexism and societal roles, time and expense required to be proficient in STEM, lack of encouragement and role models/mentors, personal expectations, and the denial of barriers.

In one form or another, half of the perceived barriers identified in this study deal with male domination or influence in STEM and societal beliefs and expectations for women. These included perceived male domination, intimidation by men, and sexism, as well as a lack of support from other women and perceived lack of respect for women and comprise major threats to women who desire to pursue careers in STEM. The perceived lack of awareness of educational and career opportunities for women create additional 
challenges that must be overcome if the gender gap in STEM is to moderate. Interestingly, while still considered barriers, time, energy, and the educational expenses associated with pursuing STEM careers did not rank as high, collectively, as those obstacles associated with men or society. These findings align with Holland's (1997) suggestion that the degree of congruence between a person's personality and interest type and their work environment affects work attitudes and behaviors and is contributing to the gender gap in STEM careers.

Several obstacles were identified that were consistent with the literature including sexism, male domination, and societal gender roles, yet over $80 \%$ of the third-round panelists in this study identified the minimization of barriers as a perceived challenge. While some may perceive the minimization of barriers as a decrease in barriers, according to social psychology theory, this may not be the case. Minimization of barriers refers to a lack of awareness of discrimination (Kaiser \& Major, 2006) and is grounded in the cultural belief that individuals possess free will and largely control their own destiny (Fiske et al., 1997). This meritocratic worldview creates the perception that successful people are responsible for and deserve their success through hard work, and individuals who simply do not work hard enough experience failure (Kaiser \& Major, 2006). However, while a distinct cultural belief in our society, this finding seems incongruous with the societal barriers also identified in this study. The panelists recognized several social or cultural barriers as well as the minimization of barriers. Has society influenced women into believing that discriminatory behaviors are foundational to their perceived failures and are not worthy of pursuing careers outside of social norms? Additional research into this complex issue is warranted.

Career and technical education (CTE) is well-prepared to make a significant impact on the gender gap in STEM, as our profession is grounded in promoting career success among secondary and postsecondary students. As over $90 \%$ of the third-round panelists in this study identified a lack of awareness of educational and career opportunities in STEM as a barrier to pursuit of STEM careers, it is recommended that CTE teacher educators continue to prepare preservice teachers to enter the classroom with the tools to promote the educational and career opportunities that exist in STEM. STEM career readiness concepts are naturally inherent within the various domains of career and technical education (Swafford, 2018). It is imperative that CTE teachers incorporate STEM concepts into their programs to ensure students are exposed to the opportunities which exist and, more importantly, are educated about social and cultural issues surrounding STEM, in an effort to make this career field more inclusive of women.

The responsibility of educating girls and young women about the educational and career options in STEM does not rest solely with formal CTE educators, however. Agricultural communications and extension professionals, for example, have the unique opportunity to use their informal and non-formal educational platforms to promote STEM to this underrepresented population. We recommend that communications professionals utilize print, video, audio, and social media platforms as tools to educate girls and young women about the educational and career opportunities in STEM. We further recommend that these platforms be used to target boys and young men in an attempt to dispel misconceptions about females and their roles in society and the modern workforce. Youth extension professionals are also encouraged to use their positions as mentors and role 
models to support and embolden girls and young women to pursue STEM careers and further educate boys and young men about the negative impact of gender bias and discrimination. Finally, we recommend that industry develop training and gender balanced promotional materials for STEM-based careers.

Regarding future research, we recommend that future research focus on the efficacy of formal, informal, and non-formal education models toward increasing awareness of educational and career opportunities in STEM. Researching effective methods to recruit and retain females in STEM degree programs is also suggested. We also suggest research into CTE training and promotional materials to identify potential gender inequality. We further recommend analyzing training and promotion materials developed by industry for STEM-based careers for gender bias. Finally, we recommend that research be conducted to determine the most effective mentoring programs to support young women as they pursue STEM education and careers.

\section{References}

American Society for Quality. (2009). Engineering image problem could fuel shortage. Milwaukee, WI: American Society for Quality.

Andreescu, T., Gallian, J. A., Kane, J. M., \& Mertz, J. E. (2008). Cross-cultural analysis of students with exceptional talent in mathematical problem solving. Notices of the American Mathematical Society, 55, 1248-1260.

Ary, D., Jacobs, Razavieh, A, \& Sorenson, C. (2006). Introduction to research in education (7th ed.). Belmont, CA: Thomson Wadsworth.

Carnevale, A. P., Smith, N., \& Melton, M. (2011). STEM state-level analysis: Science, technology, engineering, mathematics. Washington, DC: Georgetown University Center on Education and the Workforce.

Ceci, S. J., Williams, W. M., \& Barnett, S. M. (2009). Women's underrepresentation in science: Sociocultural and biological considerations. Psychological Bulletin, 135(2), 218261.https://doi.org/10.1037/a0014412

Corbett, C., Hill, C., \& St. Rose, A. (2008). Where the girls are: The facts about gender equity in education. Washington, DC: American Association of University Women.

Dalkey, N.C. (1969). The Delphi method: An experimental study of group opinion. Santa Monica, CA: The Rand Corporation.

Delp, P., Thesen, A., Motiwalla, J., \& Seshadri, N. (1977). Delphi: System tools for project planning. Columbus, OH: National Center for Research in Vocational Education, Ohio State University.

Dweck, C. (2006). Is math a gift? Beliefs that put females at risk. In S. J. Ceci \& W. M. Williams (Eds.), Why aren't more women in science? Top researchers debate the evidence (pp. 47-55). Washington, DC: American Psychological Association.

Eccles, J. S. (2006). Where are all the women? Gender differences in participation in physical science and engineering. In S. J. Ceci \& W. M. Williams (Eds.), Why aren't more women in science? Top researchers debate the evidence (pp. 199-210). Washington, DC: American Psychological Association

Fiske, A. P., Kitayama, S., Markus, H. R., \& Nisbett, R. E. (1997). The cultural matrix of social psychology. In D. T. Gilbert, S. T. Fiske, \& G. Lindzey (Eds.). The handbook of social psychology (pp. 915-981), Boston: McGraw-Hill. 
Ginther. D. K., \& Kahn, S. (2006). Does science promote women? Evidence from academia 1973-2001 (NBER Working Paper W12691). Cambridge, MA: National Bureau of Economic Research.

Guiso, L., Monte, F., Sapienza, P., \& Zingales, L. (2008). Diversity. Culture, gender, and math. Science, 320, 1164-1165. https://doi.org/10.1126/science.1154094

Halpern, D. F., Benbow, C. P., Geary, D. C., Gur, R. C., Hyde, J. S., \& Gernsbacher, M. A. (2007). The science of sex differences in science and mathematics. Psychological Science in the Public Interest, 8(1), 1-51. https://doi.org/10.1111/j.1529-1006.2007.00032.x.

Hartung, P. J., Porfeli, E. J., \& Vondracek, F. W. (2005). Child vocational development: A review and reconsideration. Journal of Vocational Behavior, 66(3), 385-419. https://doi.org/10.1016/j.jvb.2004.05.006

Hedges, L. V., \& Nowell, A. (1995). Sex differences in mental test scores, variability, and numbers of high-scoring individuals. Science, 269, 41-45. https://doi.org/10.1126/science.7604277

Hewlett, S. A., Buck Luce, C., Servon, L. J., Sherbin, L., Shiller, P., Sosnovich, E., \& Sumberg, K. (2008). The Athena Factor: Reversing the brain drain in science, engineering and technology (Harvard Business Review Research Report). Boston: Harvard Business Publishing.

Hill, C., Corbett, C., \& St. Rose, A. (2010). Why so few? Women in science, technology, engineering, and mathematics. Washington, DC: American Association of University Women.

Holland, J. L. (1997). Making vocational choices: A theory of vocational personalities and work environments (3rd ed.). Odessa, FL: Psychological Assessment Resources.

Hyde, J. S., Lindberg, S. M., Linn, M. C., Ellis, A. B., \& Williams, C. C. (2008). Gender similarities characterize math performance. Science, 321, 494-495. https://doi.org/10.1126/science.1160364

Kaiser, C. R., \& Major, B. (2006). A social psychological perspective on perceiving and reporting discrimination. Law \& Social Inquiry, 31(4), 801-830. https://doi.org/ 10.1111/j.17474469.2006.00036.x

Kimura, D. (2002). Sex hormones influence human cognitive pattern. Neuroendocrinology Letters, 23(Suppl.4), 67-77.

Lambeth, J. M., Elliott, J., \& Joerger, R. (2008). The national career and technical education research agenda. Techniques, 83(7), 52-55.

Linn, M. C., \& Petersen, A. C. (1985). Emergence and characterization of sex differences in spatial ability: A meta-analysis. Child Development, 56, 1479-1498. https://doi.org/10.2307/1130467

Low, K. S. D., Yoon, M., Roberts, B. W., \& Rounds, J. (2005). The stability of vocational interests from early adolescence to middle adulthood: A quantitative review of longitudinal studies. Psychological Bulletin, 131(5), 713-737. https://doi.org/10.1037/0033-2909.131.5.713

Lubinski, D., \& Benbow, C. P. (2006). Study of mathematically precocious youth after 35 years: Uncovering antecedents for the development of math-science expertise. Perspectives on Psychological Science, 1(4), 316-345. https://doi.org/10.1111/j.1745-6916.2006.00019.x

Lynn, R., \& Irwing, P. (2004). Sex differences on the progressive matrices: A meta-analysis. Intelligence, 32(5), 481-498. https://doi.org/10.1016.j.intell.2004.06.008

National Science Board. (2014). Science and Engineering Indicators 2014. Arlington VA: National Science Foundation (NSB 14-01) 
National Science Foundation. (2009). Characteristics of doctoral scientists and engineers in the United States: 2006 (NSF09-317). Arlington, VA: National Science Foundation.

Pajares, F. (2005). Gender differences in mathematics self-efficacy beliefs. In A. M. Gallagher \& J. C. Kaufman (Eds.), Gender differences in mathematics: An integrative psychological approach (pp. 294-315). Boston: Cambridge University Press.

Roberts, T. G., Harder, A., \& Brashears, M. T. (Eds). (2016). American Association for Agricultural Education national research agenda: 2016-2020. Gainesville, FL: Department of Agricultural Education and Communication.

Rothwell, J. (2013). The hidden STEM economy. Washington DC: Brookings Institution.

Rothwell, J. (2014). Still searching: Job vacancies and STEM skills. Washington, DC: Brookings Institution.

Seymour, E., \& Hewitt, N. M.(1997). Talking about leaving: Why undergraduates leave the sciences. Boulder, CO: Westview Press.

Simard, C., Henderson, A. D., Gilmartin, S. K., Schiebinger, L., \& Whitney, T. (2008). Climbing the technical ladder: Obstacles and solutions for mid-level women in technology. Stanford, CA: Michelle R. Clayman Institute for Gender Research, Stanford University, \& Anita Borg Institute for Women and Technology.

Stack, S. (2004). Gender, children and research productivity. Research in Higher Education, 45(8), 891-920. https://doi.org/10.1007/s11162-004-5953-z

Stitt-Gohdes, W. L., \& Crews, T. B. (2004). The Delphi technique: A research strategy for career and technical education. Journal of Career and Technical Education, 20(2), 55-67.

Stripling, C. T., \& Ricketts, J. C. (2016). Research priority 3: Sufficient scientific and professional workforce that addresses the challenges of the 21 st century. In T. G. Roberts, A. Harder, \& M. T. Brashears (Eds.), American Association for Agricultural Education national research agenda: 2016-2020 (pp. 29-36). Gainesville, FL: Department of Agricultural Education and Communication.

Swafford, M. (2018). STEM education at the nexus of the 3-circle model. Journal of Agricultural Education, 59(1), 297-315. https://doi.org/10.5032/jae.2018.01297

United States Department of Agriculture. National Agricultural Statistics Service. (2014). Farm demographics: U.S. farmers by gender, age, race, ethnicity, and more. Washington, DC: United States Department of Agriculture.

United States Department of Education. National Center for Education Statistics. (2007). The nation's report card: America's high school graduates: Results from the 2005 NAEP high school transcript study (NCES 2007-467). Washington, DC: Government Printing Office.

United States Department of Education. National Center for Education Statistics. (2015). Digest of education statistics 2013 (NCES 2015-011). Washington, DC: Government Printing Office.

United States Department of Labor. Bureau of Labor Statistics. (2009). Women in the labor force: A databook (Report 1018). Washington, DC: United States Department of Labor.

United States Department of Labor. Bureau of Labor Statistics. (2016). Labor force characteristics by race and ethnicity, 2015 (Report 1062). Washington, DC: United States Department of Labor.

Valian, V. (1998). Why so slow? The advancement of women. Cambridge, MA: MIT Press.

Weinberger, C. J. (2005). Is the science and engineering workforce drawn from the far upper tail of the math ability distribution? Available at http://econ.ucsb.edu/ weinberg/uppertail.pdf 
WGBH Educational Foundation \& Association for Computing Machinery. (2009). New image for computing: Report on market research. Victoria, Australia: WGBH Educational Foundation.

Xie, Y., \& Shauman, K. A. (2003). Women in science: Career processes and outcomes. Cambridge, MA: Harvard University Press.

Xu, Y. J. (2008). Gender disparity in STEM disciplines: A study of faculty attrition and turnover intentions. Research in Higher Education, 49(7), 607-624.

https://doi.org/10.1007/s11162-008-9097-4 